\title{
Pengujian Peladen VoIP dalam Lingkungan Operasional
}

\author{
Dany Eka Saputra ${ }^{1}$, Irfan Dhia Irsyad ${ }^{2}$, Muhammad Abdul Mujib ${ }^{3}$ \\ 1,2,3 STMIK “AMIKBANDUNG” \\ 1,2,3 Jl. Jakarta No. 28 Bandung \\ e-mail: dekastra@stmik-amikbandung.ac.id
}

\begin{abstract}
Abstrak - Pengujian peladen (server) yang sudah memasuki masa operasional menimbulkan beberapa masalah. Peladen yang berada diluar kuasa pihak penguji serta gangguan dari faktor eksternal dapat mempengaruhi hasil pengujian dan memberikan kesimpulan yang salah. Untuk itu, penelitian mengembangkan metode pengujian yang dapat mengatasi permasalahan tersebut. Metode dikembangkan untuk menguji penggunaan peladen VoIP melayani panggilan dari dan ke jaringan lokal yang berbeda. Pengujian dilakukan dengan memantau paket data yang dikirimkan selama percakapan menggunakan VoIP di perangkat percakapan. Hasil dari implementasi metode menunjukkan bahwa metode pengujian dapat memberikan kesimpulan mengenai peladen VoIP yang diuji.
\end{abstract}

Kata kunci: VoIP, pengujian operasional, metode pengujian, delay, packet loss

\section{Pendahuluan}

Voice over Internet Protocol (VoIP) merupakan teknologi yang mengirimkan data suara sebagai data digital menggunakan jaringan internet. Saat ini VoIP sudah menjadi salah satu teknologi umum untuk komunikasi dua arah secara jarak jauh. Dengan menggunakan teknologi ini, pembicaraan antara dua pihak diubah menjadi data digital. Data tersebut dikirimkan sebagai paket-paket data dengan menggunakan jaringan internet. Keandalan, kemudahan, dan biaya yang menjadi alasan penggunaan VoIP.

Kualitas dari layanan VoIP secara kuantitatif dapat dinilai dari Quality of Service (QoS). QoS memiliki beberapa parameter menggambarkan kualitas suatu layanan. Layanan VoIP sendiri dapat dilihat kualitasnya dengan menggunakan 2 parameter QoS, delay dan packet loss. Delay merupakan parameter yang menggambarkan perbedaan waktu antara pengiriman paket di asal dengan penerimaan paket di tujuan. Packet loss menyatakan rasio dari jumlah paket yang diterima di tujuan dibandingkan dengan jumlah paket yang dikirimkan oleh asal.

ITU-T memberikan standar bagi nilai yang dianggap memuaskan untuk parameter delay dan packet loss [1], [2]. Standar ini dapat digunakan sebagai titik referensi dalam pengujian layanan VoIP. Standar yang sama dapat digunakan untuk melakukan penyesuaian konfigurasi peladen (server) VoIP. Pemenuhan suatu layanan VoIP terhadap standar ini memiliki arti bahwa layanan tersebut memiliki kualitas yang dapat diterima oleh pengguna.

Pengukuran kualitas juga dapat dilakukan dengan menggunakan parameter kualitatif. Cara yang umum digunakan dalam penentuan kualitas dengan metode ini adalah Mean Opinion Score (MOS). Dengan menggunakan cara ini, pengujian dilakukan langsung pada pengguna dengan menanyakan beberapa parameter yang menggambarkan kualitas layanan yang dirasakan. Cara ini telah diajukan dalam [3].

Pengukuran dan pengujian untuk mendapatkan parameter tersebut dapat dilakukan dengan berbagai cara. Cara yang paling umum adalah dengan memantau paket data dalam traffic

TELKA, Vol.3, No.2, November 2017, pp. 84 93

ISSN (e): 2540-9123

ISSN (p): 2502-1982 
pembicaraan VoIP [4], [5], [6], [7], [8] . Pemantauan paket data memberikan data mentah yang digunakan dalam menghitung delay dan packet loss.

Meski pemantauan paket data merupakan cara yang umum, terdapat beberapa variasi dalam langkah pengambilan paket data tergantung pada obyek pengujian atau pengukuran. Kondisi jaringan [4], [5], [9], protokol yang digunakan [6], [10], dan perangkat pemantau yang digunakan [8], [11], [12], [13] memberikan variasi dalam menentukan langkah-langkah yang dilakukan dalam pengujian/pengukuran.

Pengujian tersebut selayaknya dilakukan dalam kondisi yang terkendali. Hal ini untuk meminimalkan adanya gangguan yang dapat mempengaruhi nilai parameter yang didapatkan dan mendorong kesimpulan yang salah. Namun, metode untuk melakukan pengujian sesudah deployment tetap dapat dilakukan dengan melakukan hal-hal yang mengeliminir pengaruh kondisi eksternal [9].

Dalam makalah ini, diajukan metode pengujian dalam kondisi operasional (post-deployment). Subyek uji dalam metode ini adalah konfigurasi peladen (server) VoIP. Metodologi yang diajukan dapat mengeliminir pengaruh eksternal untuk mendapatkan indikasi apakah penyesuaian yang dilakukan di peladen sudah tepat atau tidak.

\section{Metode Pengujian yang Diajukan}

Kondisi yang menjadi dasar bagi pengembangan metode uji dapat dilihat pada Gambar 1 . Dalam kondisi ini, layanan VoIP sudah diimplementasikan. Implementasi setidaknya menghubungkan 3 (tiga) perangkat: IP phone asal, peladen VoIP, dan IP phone tujuan. Tiap perangkat berada dalam jaringan lokal yang berbeda. Peladen berada pada suatu data center yang tidak berada dalam kuasa penguji. Sehingga parameter peladen tidak dapat dipantau secara langsung.

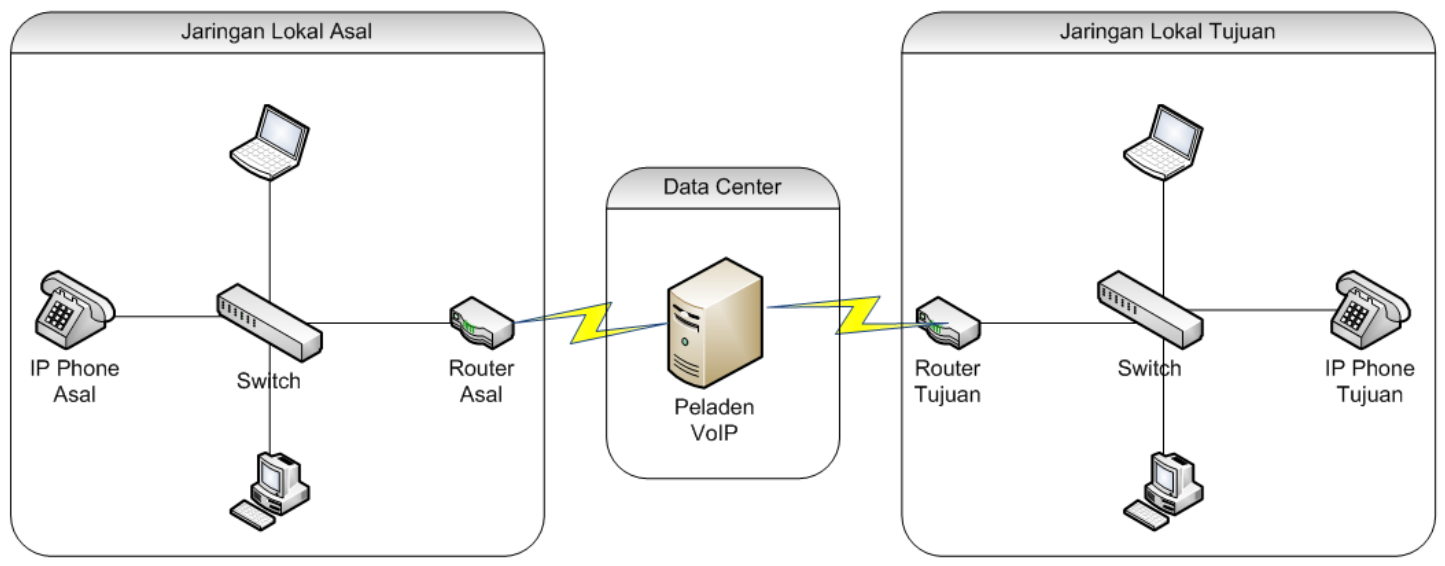

Gambar 1. Arsitektur jaringan VoIP yang menjadi dasar pengembangan

Kondisi ini menimbulkan beberapa batasan dalam melakukan pengujian. Batasan tersebut akan menentukan langkah-langkah pengujian dan juga mengubah cara perhitungan parameter QoS. Batasan tersebut adalah:

a. Waktu antar tiap perangkat tidak tersinkronisasi dan mungkin memiliki perbedaan yang cukup signifikan,

b. Traffic dalam jaringan peladen tidak dapat diketahui, sehingga pemantauan paket tidak dapat dilakukan pada peladen.

Pengujian dilakukan dengan mempertimbangkan 2 jenis traffic yang terdapat dalam kondisi uji. Outbound traffic adalah lalu lintas data keluar yang terdiri dari hop Asal-Peladen dan PeladenTujuan. Inbound traffic adalah lalu lintas data masuk yang terdiri dari hop Tujuan-Peladen dan Peladen-Asal. Keempat hop tersebut dipantau untuk mendapatkan data lalu lintas paket. 


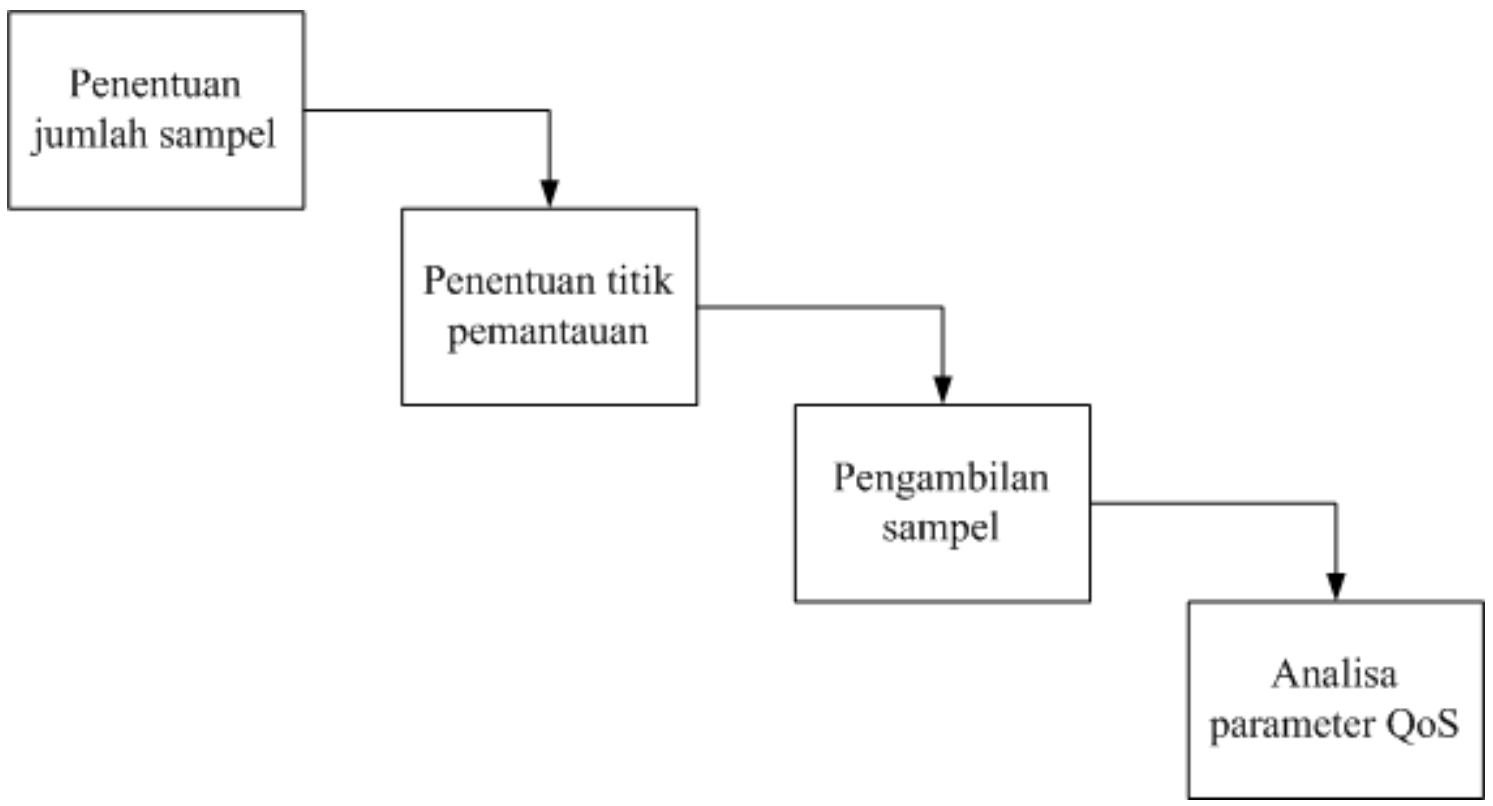

Gambar 2. Metodologi pengujian yang diajukan

Untuk mengatasi permasalahan yang sudah dijelaskan, pengujian peladen VoIP dilakukan dengan menggunakan menggunakan metodologi yang terlihat pada Gambar 2. Metodologi tersebut menjelaskan tahapan dari mulai perencanaan pengujian hingga perhitungan parameter QoS. Adapun penjelasan rinci mengenai kegiatan tiap tahap dapat dijelaskan sebagai berikut.

\subsection{Penentuan Jumlah Sampel}

Langkah pertama dalam pengujian adalah perencanaan jumlah sampel yang akan diambil. Sampel yang dimaksud adalah data paket percakapan antara Asal dengan Tujuan. Penentuan jumlah sampel akan menentukan kemampuan penguji untuk menganalisa apakah hasil yang diperoleh merupakan pengaruh dari kondisi eksternal atau konfigurasi dalam peladen itu sendiri. Jumlah sampel juga harus ditentukan untuk memastikan bahwa data inbound dan outbound memiliki porsi yang sama. Penentuan jumlah sampel dilakukan dengan menggunakan panduan berikut:

a. Sampel harus mencakup seluruh kemungkinan kondisi jaringan lokal. Sampel harus diambil saat kondisi jaringan lokal (baik di Asal maupun Tujuan) dalam kondisi high traffic maupun low traffic. Hal ini terutama dilakukan pada kondisi jaringan lokal yang tidak membedakan penggunaan VoIP dengan penggunaan lainnya.

b. Untuk kondisi high dan low traffic, pengambilan sampel dilakukan berulang. Pengulangan dilakukan dalam jumlah yang dapat meyakinkan bahwa pola yang diperoleh dari sampel selalu berulang untuk kondisi yang sama.

c. Durasi percakapan pada tiap sampel harus dibuat agar inbound dan outbound traffic memiliki jumlah paket yang kurang lebih sama. Hal ini bisa dilakukan dengan merancang percakapan yang saling bergantian dalam jangka waktu tertentu (misal per 5 detik).

Penentuan jumlah sampel dapat didekati dengan menggunakan persamaan berikut:

$$
s \approx C_{2}^{n} \times m
$$

dengan $C$ adalah jumlah kombinasi dari kondisi traffic di Asal dan Tujuan, $n$ adalah jumlah total kondisi traffic pada tiap jaringan lokal, dan $m$ adalah jumlah pengulangan untuk tiap kombinasi traffic. 


\subsection{Penentuan Titik Pemantauan}

Titik pemantauan adalah titik di mana perangkat lunak pemantauan traffic diletakkan. Penentuan titik pemantauan bergantung pada kondisi akses perangkat dan juga kemampuan perangkat lunak yang digunakan. Untuk lebih jelasnya lihat Gambar 3.

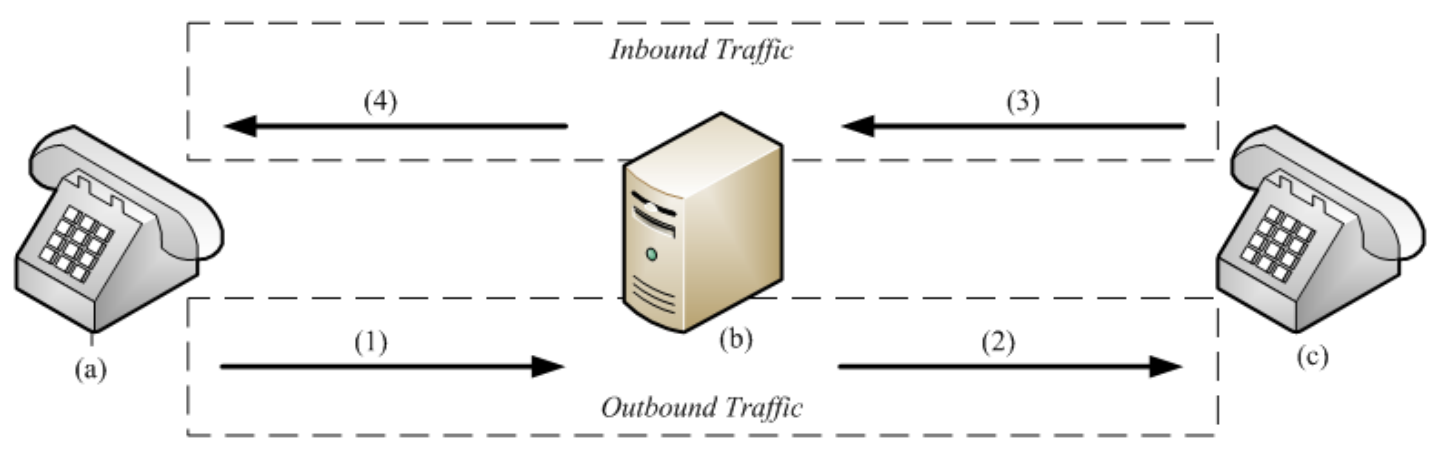

Gambar 3. Alur data pada sistem yang diuji

Pada Gambar 3 terdapat 3 titik yang mungkin digunakan sebagai titik pemantauan. Titik (a) adalah IP phone pada Asal, titik (b) adalah peladen VoIP, dan titik (c) adalah IP phone pada Tujuan. Secara ideal, pemantauan harus dilakukan pada ketiga titik tersebut untuk memantau keempat traffic hop yang ada (dilambangkan dengan subset angka). Namun dari batasan yang sudah dinyatakan sebelumnya, peladen tidak mungkin digunakan sebagai titik pantau

Bila perangkat pemantauan mampu memantau keempat data melalui satu titik pantau, maka cukup salah satu antara titik (a) atau (b) yang digunakan. Namun, demi kualitas data yang lebih baik, sebaiknya kedua titik pemantauan digunakan untuk memantau data traffic.

\subsection{Pengambilan Sampel}

Sampel diambil dengan melakukan panggilan dari telepon Asal ke telepon Tujuan. Pada tiap pengambilan sampel sebaiknya disediakan skenario percakapan yang sudah disiapkan sebelumnya. Skenario tersebut harus dapat memastikan bahwa durasi tiap pengambilan sampel sama, sehingga menghasilkan jumlah paket yang kurang lebih sama.

Skenario juga memastikan bahwa tiap dialog yang digunakan antara Asal-Tujuan dan Tujuan-Asal memiliki durasi yang sama. Hal ini dilakukan untuk memastikan bahwa data inbound dan outbound memiliki porsi yang hampir sama. Sebagai contoh, setiap kali Asal berbicara, durasinya dibatasi selama 10 detik. Setelah itu, giliran Tujuan berbicara dengan durasi yang sama. Giliran tersebut diulangi hingga total durasi yang sudah ditetapkan tercapai untuk tiap sampel.

Hasil dari pengujian ini memiliki variasi tergantung perangkat lunak yang digunakan untuk melakukan pemantauan. Secara umum, data yang diperoleh dari pengujian yang relevan untuk fase analisa ada 3 jenis data yang tergabung dalam satu paket. Data tersebut adalah source IP, destination IP, protokol paket, dan waktu pengiriman/penerimaan paket.

\subsection{Analisa Parameter QoS}

Setelah data sampel diambil langkah terakhir dalam pengujian adalah analisa parameter QoS. Tujuan dari langkah ini adalah menentukan apakah penyesuaian yang dilakukan pada peladen VoIP sudah benar dan memberikan layanan yang sesuai standar. Analisa dilakukan dengan langkah-langkah berikut:

a. Memisahkan sampel berdasarkan kombinasi traffic yang sudah ditentukan.

b. Menyaring data paket dalam tiap kelompok sampel berdasarkan protokol. Pada langkah pertama ini, hanya data paket yang memiliki protokol RTP yang diambil dan membuang 
paket dengan protokol lainnya. Data percakapan terkadung pada paket yang memiliki protokol RTP.

c. Memisahkan data berdasarkan source IP dan destination IP dan menggolongkannya berdasarkan hop traffic. Setelah langkah ini untuk tiap kombinasi traffic terdapat 4 kelompok data berdasarkan hop, Asal-Peladen, Peladen-Tujuan, Tujuan-Peladen, dan Peladen-Asal.

d. Menghitung parameter QoS pada tiap kelompok data. Parameter yang dihitung adalah delay dan packet loss. Parameter disandingkan berdasarkan kelompok traffic untuk melihat pola delay dan packet loss selama pengujian.

e. Menganalisa pola delay dan packet loss untuk mengeliminasi faktor eksternal dan menentukan hasil penyesuaian peladen VoIP. Pola parameter QoS yang diperoleh bisa dibandingkan dengan data penggunaan bandwith pada jaringan lokal saat pengujian dilakukan.

Packet loss dapat dihitung dengan menggunakan persamaan berikut:

$$
P L=\frac{P_{r}}{P_{s}} \times 100 \%
$$

dengan $P L$ adalah rasio paket yang hilang atau packet loss $(\%), P_{S}$ adalah jumlah paket yang dikirimkan oleh Asal, dan $P_{r}$ adalah jumlah paket yang diterima oleh Tujuan. berikut:

Perhitungan delay untuk tiap paket dapat dilakukan dengan menggunakan persamaan

$$
d=T_{a}-T_{s}
$$

dengan $T_{a}$ adalah waktu penerimaan paket di Tujuan, $T_{s}$ adalah waktu pengiriman paket di Asal, dan delay $(d)$ dinyatakan dalam satuan detik. Dengan demikian delay rata-rata untuk tiap sampel dapat dihitung dengan menggunakan:

$$
a v d=\frac{\sum_{i=1}^{j} d_{i}}{P_{S}}
$$

dengan avd adalah delay rata-rata (detik), dan $d_{i}$ adalah delay tiap paket.

Namun, (3) dan (4) tidak dapat digunakan dalam kondisi yang menjadi dasar penelitian ini. Dalam batasan yang sudah dijelaskan, kondisi di peladen merupakan sebuah kotak hitam yang tidak dapat diamati. Dari langkah penentuan titik pantau juga sudah dijelaskan bahwa tidak ada titik pantau pada peladen sehingga waktu pengiriman atau penerimaan paket di peladen tidak dapat ditentukan. Selain itu, (3) secara implisit menyaratkan waktu di titik pengiriman dan penerimaan tersinkronisasi dengan baik. Namun berdasarkan batasan pertama, kondisi ini tidak memungkinkan. Dengan demikian, kita membutuhkan cara lain untuk menghitung delay rata-rata untuk tiap sampel.

Dari pengumpulan dan pemisahan data berdasarkan protokol, kita dapat menentukan durasi percakapan untuk tiap hop. Durasi total percakapan yang diperoleh merupakan gabungan dari durasi percakapan ditambah dengan total delay, atau secara matematis dinyatakan sebagai,

$$
T_{\text {sampel }}=T_{c}+d_{\text {total }}
$$

dengan $T_{\text {sampel }}$ adalah durasi total dari sampel (detik), $T_{c}$ adalah durasi total percakapan (detik), dan $d_{\text {total }}$ adalah total delay untuk sampel tersebut (detik). Yang diperoleh dari pengambilan sampel adalah variabel $T_{\text {sampel }}$. Karena variabel tersebut sudah mengandung delay untuk tiap paket, kita dapat menentukan perkiraan rata-rata delay per paket (average expected delay per packet) sebagai berikut:

$$
a d p=\frac{T_{\text {sampel }}}{P_{S}}
$$


Persamaan (6) akan menggantikan (3) dan (4) untuk menghitung parameter delay. Meskipun demikian patut dicatat bahwa $a d p$ adalah suatu pendekatan, bukan delay yang sebenarnya. Hal ini didasarkan pada asumsi bahwa berdasarkan (5) delay sebenarnya akan lebih kecil atau sama dengan perkiraan delay (avd $\leq a d p)$.

\section{Analisis Implementasi}

Metode pengujian yang dijelaskan pada bagian sebelumnya sudah diimplementasikan untuk menguji konfigurasi peladen VoIP yang sudah beroperasi. Pada bagian ini, contoh implementasi tersebut diberikan untuk memberikan validasi bahwa metodologi yang dikembangkan memang dapat mencapai tujuan yang sudah dijelaskan pada awal makalah. Sistem yang menjadi obyek pengujian memiliki arsitektur jaringan seperti yang terlihat pada Gambar 1. Antar jaringan dihubungkan dengan menggunakan virtual private network (VPN). Namun, fakta ini tidak memiliki kontribusi pada parameter QoS yang dicari sehingga dikesampingkan dalam pengujian.

\subsection{Penentuan Jumlah Sampel}

Kondisi traffic pada sistem yang diuji menghasilkan kondisi sebagai berikut: Pagi, Siang, dan Sore. Dalam hal ini, 3 kondisi tersebut sudah menghasilkan kombinasi yang ada, sehingga jumlah kombinasi $\left(C_{2}^{n}\right)$ adalah 3 (tiga). Jumlah pengulangan $(m)$ yang diambil adalah 3 . Berdasarkan (1), jumlah sampel yang dibutuhkan adalah 9 (sembilan) sampel.

\subsection{Penentuan Titik Pemantauan}

Sesuai dengan yang telah dijelaskan pada bagian sebelumnya, titik pemantauan diletakkan pada perangkan IP phone Asal dan Tujuan. Pemantauan dilakukan dengan menggunakan perangkat lunak Wireshark. Pemantauan dilakukan secara on-site pada Asal dan Tujuan secara simultan.

\subsection{Pengambilan Sampel}

Pengujian atau pengambilan sampel dilakukan selama 3 hari. Setiap hari dilakukan pengambilan sampel pada pagi, siang, dan sore. Durasi percakapan untuk tiap sampel adalah \pm 5 menit, dengan porsi untuk inbound dan outbound masing-masing $\pm 2,5$ menit. Rincian langkah pengambilan sampel yang dilakukan dapat dilihat pada Tabel 1.

Tabel 1. Rincian pengambilan sampel

\begin{tabular}{ccccc}
\hline Hari & Waktu & Durasi outbound & Durasi inbound & $\begin{array}{c}\text { Total durasi } \\
\text { percakapan }\end{array}$ \\
\hline $\mathbf{1}$ & Pagi & $\pm 2,5$ menit & $\pm 2,5$ menit & \pm 5 menit \\
& Siang & $\pm 2,5$ menit & $\pm 2,5$ menit & \pm 5 menit \\
& Sore & $\pm 2,5$ menit & $\pm 2,5$ menit & \pm 5 menit \\
$\mathbf{2}$ & Pagi & $\pm 2,5$ menit & $\pm 2,5$ menit & \pm 5 menit \\
& Siang & $\pm 2,5$ menit & $\pm 2,5$ menit & \pm 5 menit \\
& Sore & $\pm 2,5$ menit & $\pm 2,5$ menit & \pm 5 menit \\
$\mathbf{3}$ & Pagi & $\pm 2,5$ menit & $\pm 2,5$ menit & \pm 5 menit \\
& Siang & $\pm 2,5$ menit & $\pm 2,5$ menit & \pm 5 menit \\
& Sore & $\pm 2,5$ menit & $\pm 2,5$ menit & \pm 5 menit \\
\hline
\end{tabular}

\subsection{Analisa QoS}

Pada langkah ini, pemisahan dan penyaringan sampel berdasarkan metodologi yang dikembangkan sudah dilakukan pada sampel yang diperoleh. Berdasarkan penyaringan, diperoleh 36 kelompok data yang akan dihitung parameter delay dan packet loss. Dengan menggunakan (2) 
dan (6), delay dan packet loss tiap kelompok data dihitung. Hasil yang diperoleh dapat dilihat pada Tabel 2.

Tabel 2. Hasil perhitungan delay dan packet loss pada sampel

\begin{tabular}{|c|c|c|c|c|c|c|c|c|}
\hline \multirow{2}{*}{$\begin{array}{c}\text { Kelompok } \\
\text { Sampel }\end{array}$} & \multicolumn{2}{|c|}{ Asal-Peladen } & \multicolumn{2}{|c|}{ Peladen-Tujuan } & \multicolumn{2}{|c|}{ Tujuan-Peladen } & \multicolumn{2}{|c|}{ Peladen-Asal } \\
\cline { 2 - 9 } & $(\mathbf{m s})$ & $\begin{array}{c}\text { Packet } \\
\text { Loss } \\
(\%)\end{array}$ & $\begin{array}{c}\text { Delay } \\
(\mathbf{m s})\end{array}$ & $\begin{array}{c}\text { Packet } \\
\text { Loss } \\
(\boldsymbol{\%})\end{array}$ & $\begin{array}{c}\text { Delay } \\
(\mathbf{m s})\end{array}$ & $\begin{array}{c}\text { Packet } \\
\text { Loss } \\
(\boldsymbol{\%})\end{array}$ & $\begin{array}{c}\text { Delay } \\
(\mathbf{m s})\end{array}$ & $\begin{array}{c}\text { Packet } \\
\text { Loss } \\
(\boldsymbol{\%})\end{array}$ \\
\hline Pagi 1 & 20,004 & 0,013 & 20,069 & 0,33 & 20,272 & 0,965 & 20,302 & 0 \\
\hline Pagi 2 & 19,999 & 0 & 19,997 & 0,013 & 20,012 & 0 & 20,012 & 0 \\
\hline Pagi 3 & 19,953 & 0 & 20,588 & 2,85 & 19,999 & 0 & 20,078 & 0 \\
\hline Siang 1 & 19,997 & 0 & 20,599 & 2,92 & 22,100 & 8,69 & 22,126 & 0 \\
\hline Siang 2 & 19,997 & 0 & 20,496 & 2,42 & 25,312 & 4,46 & 20,978 & 0 \\
\hline Siang 3 & 19,997 & 0 & 20,148 & 0,708 & 20,012 & 0,064 & 20,022 & 0 \\
\hline Sore 1 & 19,999 & 0 & 20,153 & 0,758 & 20,131 & 0,05 & 20,121 & 0 \\
\hline Sore 2 & 19,998 & 0 & 20,114 & 0,577 & 20,063 & 0 & 20,078 & 0 \\
\hline Sore 3 & 20,014 & 0,083 & 35,295 & 42,63 & 21,088 & 5,17 & 21,224 & 0,189 \\
\hline
\end{tabular}

Mengacu pada Tabel 2, delay pada sampel menunjukkan nilai rata-rata \pm 20 milidetik. Namun, patut diingat bahwa standar delay yang diberikan pada [2] mengacu pada perbedaan waktu antara pengiriman di IP phone pemanggil dengan waktu penerimaan di IP phone penerima. Dengan demikian, untuk setiap sampel panggilan telepon VoIP memiliki delay rata-rata sebesar \pm 40 milidetik. Berdasarkan standar yang disebutkan pada [1] dan [2], nilai tersebut masih termasuk pada nilai delay yang bisa diterima. Nilai delay tersebut diperoleh dari (6) yang merupakan perkiraan nilai maksimum delay rata-rata, yang dapat disimpulkan bahwa delay ratarata sesungguhnya masih lebih kecil dari nilai tersebut. Dengan ini, kita dapat menyimpulkan bahwa konfigurasi peladen sudah disesuaikan dengan baik sehingga delay tidak mempengaruhi kualitas layanan VoIP. Pola delay yang terlihat pada Gambar 4 menunjukkan bahwa delay cenderung konstan sepanjang waktu pengujian, kecuali pada sampel Sore 3 dengan hop Peladen-Tujuan.

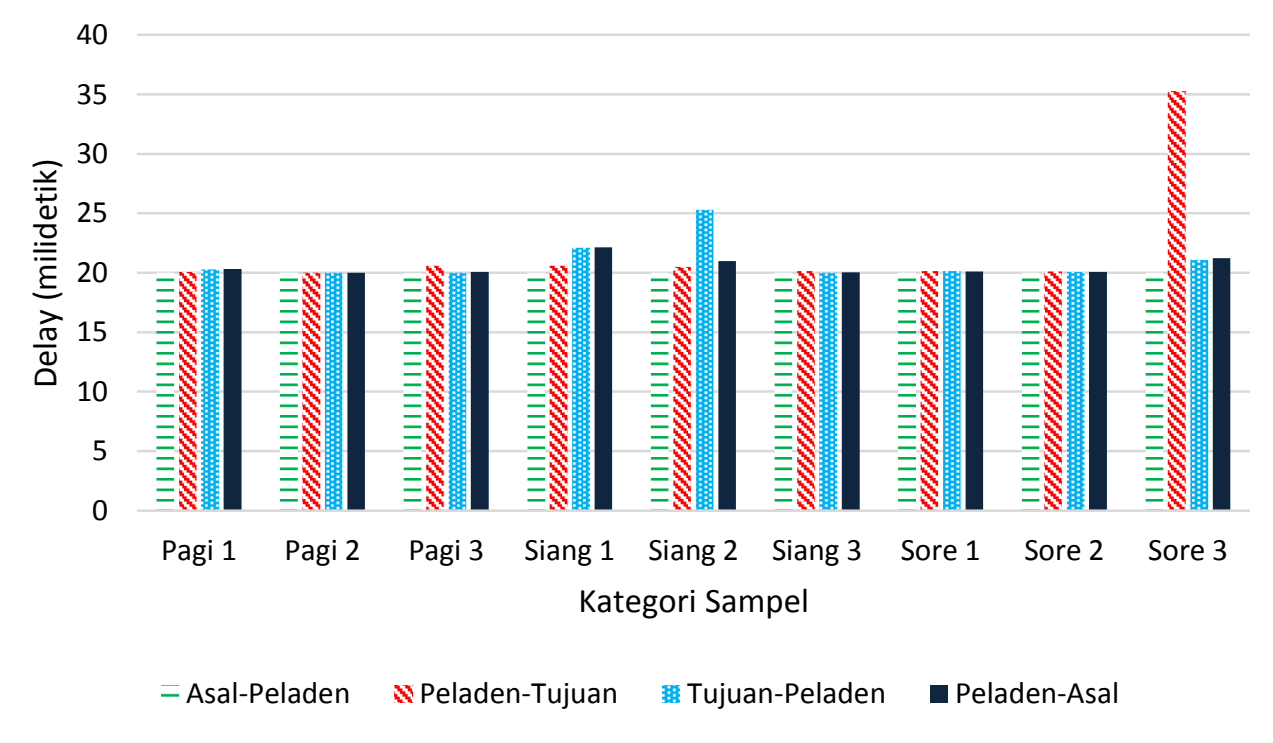

Gambar 4. Nilai delay pada tiap kategori sampel 
Packet loss harus dijaga agar tidak lebih dari 5\% [1] agar kualitas layanan VoIP masih dapat diterima. Pada Tabel 2 ada beberapa sampel yang memiliki nilai packet loss $>5 \%$, yaitu pada sampel Siang 1 dan Sore 3. Hasil ini menunjukkan indikasi bahwa layanan VoIP mengalami penurunan kualitas. Namun, hal ini tidak semerta-merta memberikan kesimpulan bahwa ada konfigurasi di peladen yang bermasalah. Untuk dapat menyimpulkan penyebab terjadinya packet loss yang melebihi standar, analisa pola packet loss untuk mengeliminir faktor eksternal. Pola packet loss dapat dilihat pada Gambar 5.

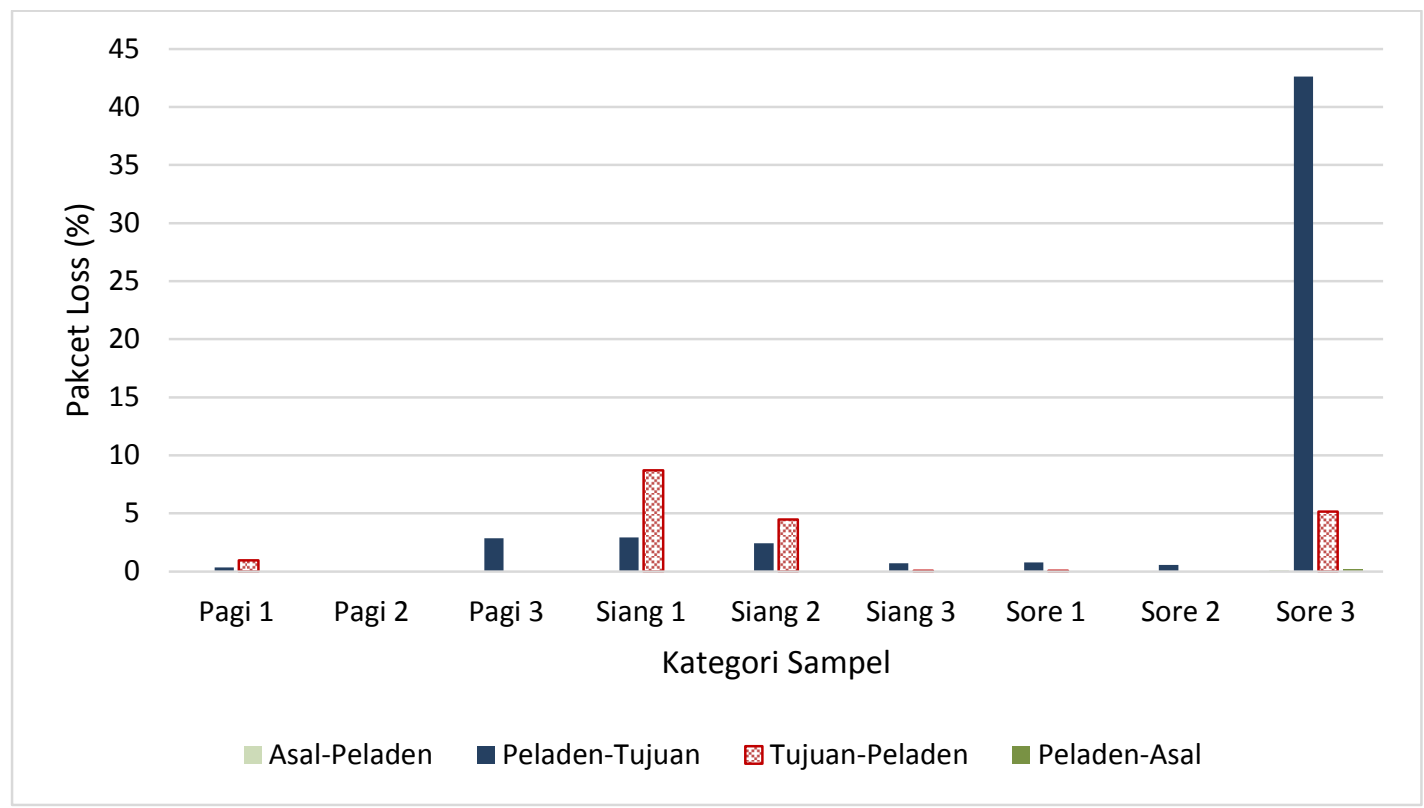

Gambar 5. Nilai Packet Loss per kategori sampel

Grafik yang terlihat pada Gambar 5 tidak menunjukkan suatu pola yang teratur. Secara umum, packet loss bernilai sangat kecil namun memiliki beberapa lonjakan yang melebihi batas yang diinginkan. Pada titik ini, dapat disimpulkan bahwa penurunan kualitas layanan tersebut tidak disebabkan oleh peladen. Dengan demikian, konfigurasi pada peladen sudah disesuaikan dengan tepat.

Untuk mendukung kesimpulan tersebut, kita bisa melihat beberapa premis pendukung yang diperoleh dari analisis pola pada Gambar 5. Premis-premis tersebut adalah sebagai berikut:

a. Packet loss lebih sering terjadi pada hop yang melibatkan Tujuan dibandingkan dengan Asal. Hal ini mengindikasikan kemungkinan bahwa paket hilang pada jaringan lokal di Tujuan.

b. Nilai packet loss terbesar terjadi pada sampel Sore 3 dengan hop Peladen-Tujuan (42\%).

Paket yang hilang tersebut berasal dari sampel Sore 3 hop Asal-Tujuan. Pada data tersebut, packet loss $<1 \%$. Hal ini mengindikasikan bahwa packet loss yang sangat besar tersebut tidak terjadi akibat pengaruh peladen. Bila premis ini digabungkan dengan premis a, maka bisa disimpulkan gangguan terjadi pada jaringan lokal Tujuan.

Analisis ini dapat diperkuat dengan membandingkan traffic pada jaringan lokal dengan data packet loss dan delay yang diperoleh. Pada implementasi ini, data traffic pada jaringan lokal Asal dapat diperoleh dan menjadi bahan perbandingan. Perbandingan tersebut dapat dilihat pada Gambar 6. 


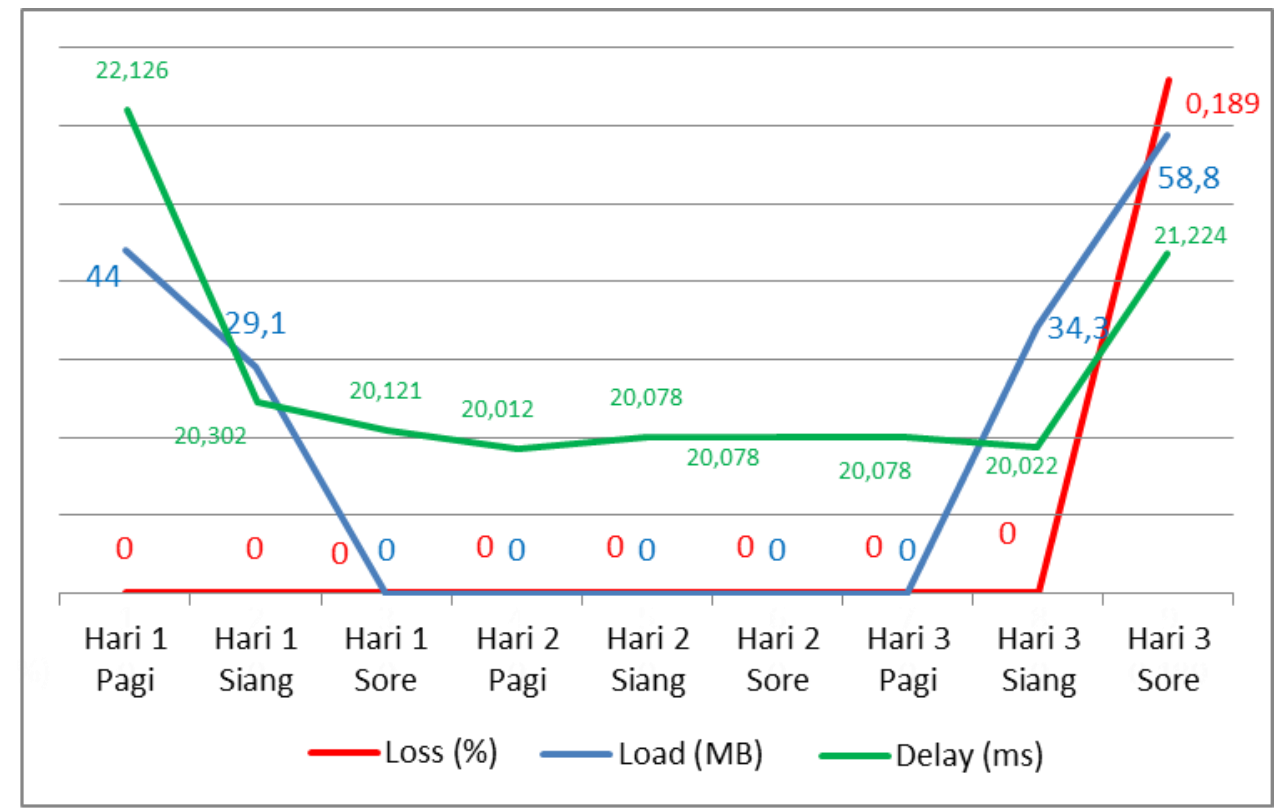

Gambar 6. Perbandingan delay, packet loss Peladen-Asal dengan traffic jaringan lokal Asal

Pola yang terlihat pada Gambar 6 menunjukkan adanya korelasi antara peningkatan nilai delay, packet loss dengan peningkatan traffic pada jaringan lokal. Penurunan kualitas layanan (delay atau packet loss naik) terjadi saat traffic mengalami kenaikan (sebagai contoh Pagi 1 dan Pagi 3). Sementara saat traffic stabil dan rendah, kualitas layanan VoIP juga menunjukkan pola yang stabil dengan nilai parameter QoS pada rentang yang dapat diterima.

Seluruh analisis yang sudah dilakukan memberikan kesimpulan bahwa faktor eksternal di luar peladen memberikan kontribusi yang cukup signifikan terhadap parameter layanan VoIP. Bila kita mengeliminir faktor eksternal tersebut, akan diperoleh kesimpulan bahwa peladen sudah memberikan layanan VoIP dengan tingkat layanan yang dapat diterima. Dengan kata lain, peladen sudah disesuaikan dengan baik untuk memberikan tingkat pelayanan yang baik.

\section{Kesimpulan}

Implementasi yang dilakukan menunjukkan kemangkusan metode dalam pengujian di lingkungan operasional. Meski kondisi dalam peladen tidak dapat diketahui secara langsung, pengujian tetap masih bisa dilakukan dengan menganalisa data-data yang diperoleh dari perangkat yang terhubung dengan peladen. Metode pengujian juga menunjukkan bahwa sinkronisasi waktu tidak perlu dilakukan antara seluruh jaringan yang terlibat dalam pengujian. Metode pengujian juga andal dalam menangani noise dari faktor eksternal yang mungkin memengaruhi hasil pengujian.

Metode yang dikembangkan cukup baik bila digunakan untuk melakukan pengujian yang melibatkan satu panggilan VoIP. Keandalan dan kemangkusan metode belum diuji untuk melakukan pengujian yang melibatkan banyak panggilan VoIP secara bersamaan. Peluang masih terbuka untuk menguji metode ini pada pengujian yang melibatkan banyak panggilan. Selain itu, masih terbuka kemungkinan bahwa metode ini membutuhkan penyesuaian agar bisa diterapkan pada pengujian dengan banyak panggilan VoIP secara bersamaan. 


\section{Daftar Pustaka}

[1] K. Gonia, "Latency and QoS for Voice over IP," SANS Institute InfoSec Reading Room, version, vol. 2, 2004.

[2] ITU-T, Rec. G-114: One-way transmission time, ITU-T, 2003.

[3] R. G. Cole and J. H. Rosenbluth, "Voice over IP performance monitoring," ACM SIGCOMM Computer Communication Review, vol. 31, no. 2, pp. 9-24, 2001.

[4] E. Najwaini and A. Ashari, "Analisis Kinerja Voip Server pada Wireless Access Point," IJCCS (Indonesian Journal of Computing and Cybernetics Systems), vol. 9, pp. 89--100, 2014.

[5] A. Pradipta, A. W. W. Nugraha and I. Setiawan, "Unjuk Kerja Voice Over Internet Protocol pada Jaringan Lokal Universitas Jenderal Soedirman," Dinamika Rekayasa, vol. 8, pp. 56$-62,2016$.

[6] K. D. Suryawan, M. Husni and E. L. Anggraini, "Analisis Layanan Kinerja Jaringan VoIP Pada Protokol SRTP Dan VPN," Institut Teknologi Sepuluh Nopember, Surabaya, 2012.

[7] T. A. B. Susanto, A. Syarif and A. Wahab, "Implementasi Dan Analisis Kualitas Layanan Voip Pada Jaringan Ad Hoc Peer-To-Peer," in Seminar Nasional Aplikasi Teknologi Informasi (SNATI), 2012.

[8] D. Mosberger and T. Jin, "httperf - a tool for measuring web server performance," ACM SIGMETRICS Performance Evaluation Review, vol. 26, no. 3, pp. 31-37, 1998.

[9] N. Fraenkel, G. Goldstein, I. Sarig and R. Haddad, "Post-deployment monitoring and analysis of server performance". USA Patent US Patent App. 10/057,295, oct \# " 19" 2001.

[10] H. Schulzrinne, S. Narayanan and J. Lennox, "SIPstone-benchmarking SIP server performance," Columbia University, 2002.

[11] P. Bardford and M. Crovella, "Generating representative web workloads for network and server performance evaluation," in ACM SIGMETRICS Performance Evaluation Review, 1998.

[12] A. W. Rix, J. G. Beerends, M. P. Hollier and A. P. Hekstra, "Perceptual evaluation of speech quality (PESQ)-a new method for speech," in Acoustics, Speech, and Signal Processing, 2001. Proceedings.(ICASSP'01)., 2001.

[13] D. Reichman, "System and method for monitoring performance of a server system using". USA Patent US Patent 6,738,813, \\#may\\# 18 2004. 